\title{
Intimate partner violence associated with low quality of life - a cross-sectional study
}

Kjersti Alsaker ${ }^{1,2^{*}}$ (D), Bente E. Moen ${ }^{3}$, Tone Morken ${ }^{2}$ and Valborg Baste ${ }^{4}$

\begin{abstract}
Background: Quality of life among abused women in Norway in 2006 was found to be significantly low compared to women at the same age in general. The aim of this study was to examine how quality of life is associated with experience of psychological and physical violence intimate partner violence among abused women seeking help after domestic partner abuse comparted to quality of life in a random sample of women in Norway.

Methods: A cross-sectional study in a random sample of 1500 women (response rate $36 \%, n=469$ ) in Norway were performed. In addition, 191 women who sought help after domestic partner abuse were invited $(44 \%, n=84)$. The experience of intimate partner violence (IPV) and health-related quality of life were measured in both samples. The participants were divided into: "Women seeking help" after domestic partner abuse $(n=84) ;$ "Random sample, abused women" ( $n=127)$; and "Random sample, not abused women" $(n=342)$.

Results: The experience of psychological and physical violence was significantly different between the groups $(p<0.0001)$. The domains in SF-12 were significantly below $(p<0.001)$ the norm for the female population in Norway in all dimensions among the abused women in the random population sample, and even lower among the women seeking help because of IPV.

Conclusion: Intimate partner violence is clearly associated with low quality of life. The pattern found in this study is similar to the pattern found in the previous Norwegian study among abused women seeking help.
\end{abstract}

Keywords: Intimate partner violence, Abuse, Quality of life

\section{Background}

Intimate partner violence (IPV) against women is a major health problem worldwide, with a serious impact on women's physical and mental health [1-3]. IPV refers to any behaviour within an intimate relationship that causes physical, psychological or sexual harm to those in the relationship [4]. A Norwegian study found a $27 \%$ lifetime prevalence of physical IPV against women, and 9\% of these had experienced serious physical violence [5]. This has been referred to as a Nordic Paradox because the level of gender equality in Norway and other Nordic countries is high [6]. In a study about quality of life among abused women in Norwegian women's shelters in 2006, the

\footnotetext{
* Correspondence: Kjersti.Alsaker@hvl.no

${ }^{1}$ Faculty of Health and Social Sciences/ Department of Welfare and

Participation, Western Norway University of Applied Sciences, Haugeveien 28, 5005 Bergen, Norway

${ }^{2}$ National Centre for Emergency Primary Health Care, Uni Research Health,

Bergen, Norway

Full list of author information is available at the end of the article
}

reported health-related quality of life (HRQoL) was seriously low (scores 20-32) on mental health, vitality and social function just after arriving at a women's shelter [7]. The very low HRQoL reported was important to establishing a focus on this issue in health and social services in Norway [8]. Quality of life is found to be significantly low among abused women around the world $[9,10]$. When the mental health score drops from 40 to 20, suicidal ideation increases by $105 \%$ [11]. Femicide and suicide are the most serious consequences of IPV against women [3, 12-14].

The aim of this study was to examine how quality of life is associated with experience of both psychological and physical violence intimate partner violence (IPV) among abuses women seeking help from Police, Women's shelters, Alternative to Violence, Assault Centre and/or Family Guidance Centers compared to quality of life in a random population sample of women in Norway.

(c) The Author(s). 2018 Open Access This article is distributed under the terms of the Creative Commons Attribution 4.0 International License (http://creativecommons.org/licenses/by/4.0/), which permits unrestricted use, distribution, and 
Knowledge about psychical, social and mental health problems, is useful in assessing the need for health care among abused women.

\section{Methods}

\section{Participants and study design}

A cross-sectional study was performed. The questionnaire was available in both Norwegian and English to make it possible to include women with other ethnic backgrounds than Norwegian. We included two samples: The first was "Abused-Seeking help": The questionnaire was sent to institutions where women may seek help after domestic partner abuse, such as the Police, Women's shelters, Alternative to Violence, Assault Centre and Family Guidance Centers. Inclusion criteria among the women seeking help were experience of partner abuse and understanding (reading) Norwegian or English. The second sample was a random sample from the population: The questionnaire was sent to a random sample of women, picked and sent by Statistics Norway. One reminder was sent to every recipient. Inclusion criteria in the random population sample were being a woman between 18 and 70 years; living in Hordaland, Norway; had been living with a partner and understanding Norwegian or English.

\section{Psychological and physical violence}

The questionnaire consisted of questions about demographics and degrees of psychological and physical violence, as well as health-related quality of life (HRQoL). Psychological violence was measured by the Psychological Maltreatment of Women Inventory (PMWI) short form [15], containing 14 questions with five respons categories (Never, Rarely, Occasionally, Frequently and Very frequently).Physical violence was measured by the Norwegian measurement used in population studies [5], containing 12 questions with respons category yes or no, regarding both last year and before last year.

\section{Health-related quality of life}

HRQoL information was gathered using the SF-12 health survey, which consists of 12 items divided into eight scales. The SF12 is derived from the SF-36 health survey, which is one of the most widely used generic instruments to measure physical and mental health-related functioning [16]. SF-12 is tested for validity and reliability, and also tested against the SF-36 [16-19]. The scales include physical functioning, physical role, bodily pain, general health, vitality, emotional role, social functioning and mental health. Raw scores for each scale range from 0 to 100, and adjusted median scores from 0 to 50 , with lower scores reflecting poorer functioning. In this study, the standard Norwegian version was used, which asks about health situations in the past four weeks. The results from SF-12 were adjusted for age according to the general female population, such that the mean of the general population is 50 and the standard deviation is 10 .

\section{Analysis}

Only those who had been living with a partner were included in the analyses. Psychological violence was dichotomized into no (never/rarely/occasionally) or yes (frequently/very frequently). Physical violence was categorized into yes or no, regardless of if the physical violence was experienced last year or before last year. The data were analyzed in three groups "Women seeking help" after domestic partner abuse, and "Random sample, abused women" and "Random sample, not abused women".

We used mean and standard deviation (SD) to examine years of age and education in the three groups. Occurrence of different acts of physical and psychological violence was given for "Women seeking help" and "Random sample, abused women" and differences between the two groups were tested in chi square analysis. To compare mean differences in HRQoL between the three group analyses of variance (ANOVA) were used. The Bonferroni were used in the post hoc tests in the ANOVA, to adjust for multiple testing. We also compared HRQoL in the random sample of with normative adjusted data from the general population in Norway by t-test (Fig. 2). Cronbach's alpha was used to test reliability among of the dimensions of SF-12 in this study. Cronbach's alpha in the eight standardized items in this study in SF-12 varied from 0.82 in

Table 1 Sociodemographic characteristics: "women seeking help because of partner-abuse" and "random sample of abused women" in Norway

\begin{tabular}{|c|c|c|c|c|c|c|c|}
\hline & \multirow{2}{*}{\multicolumn{2}{|c|}{$\begin{array}{l}\text { Seeking help } \\
(n=82) \\
\text { Abused }\end{array}$}} & \multicolumn{4}{|c|}{$\begin{array}{l}\text { Random sample } \\
(n=469)\end{array}$} & \multirow[b]{3}{*}{$p$-value ${ }^{1}$} \\
\hline & & & \multicolumn{2}{|c|}{ Abused } & \multicolumn{2}{|c|}{ Non-Abused } & \\
\hline & Mean & (SD) & Mean & (SD) & Mean & (SD) & \\
\hline Age & 38.4 & $(11.1)$ & 42.9 & (13.6) & 45.5 & $(13.1)$ & $<0.001$ \\
\hline Year of education after primary school & 4.8 & $(3.2)$ & 5.5 & (3.1) & 5.4 & $(3.0)$ & 0.238 \\
\hline Psychological violence V/E & 28.6 & $(7.2)$ & 15.0 & $(6.7)$ & 7.9 & $(1.7)$ & $<0.001$ \\
\hline Psychological violence D/l & 25.2 & (8.7) & 12.1 & (6.4) & 7.5 & $(1.0)$ & $<0.001$ \\
\hline
\end{tabular}

${ }^{1}$ From ANOVA 
the women seeking help sample to 0.89 in the random sample of abused and not abused women. In the total sample $(n=551)$ Cronbach's alpha was 0.92 . The data were analyzed using IBM SPSS Statistics 23 for Windows.

\section{Ethical considerations}

The study was approved by the Regional Committee for Medical and Health Research Ethics.

The questionnaire does not include personal data as name, date of birth or address and are coded anonymously. The first page in the questionnaire gave information about the study and the right to decline to answer. We also included telephone number to the researcher. Completion and return of the questionnaire was seen as consent to participate in the study.

\section{Results}

In this study 551 women participated; "Women seeking help" ( $n=82)$; "Random sample" $(n=469)$. The response rate was $44 \%$ in the sample of "Women seeking help" and $36 \%$ in the random population sample. Thirteen people (2.7\%) answered in English. The women seeking help were significantly younger than the women in the population sample (Table 1). No significant difference in education was found. Physical and psychological violence were more frequently reported in the group of women seeking help than in the random population sample of abused women regarding all acts $(p<0.001)$ (Table 2$)$.

The respondents reported serious physical and psychological violence. Threats of being hurt were reported by $81 \%$ among women seeking help, and $29 \%$ among the

Table 2 Physical and psychological violence among "women seeking help because of partner-abuse" and "random sample of abused women" in Norway

\begin{tabular}{|c|c|c|c|c|}
\hline \multirow[t]{3}{*}{ Physical and psychological violence } & \multirow{2}{*}{\multicolumn{2}{|c|}{$\begin{array}{l}\text { Seeking help } \\
\text { Abused }\end{array}$}} & \multirow{2}{*}{\multicolumn{2}{|c|}{$\begin{array}{l}\text { Random sample } \\
\text { Abused }\end{array}$}} \\
\hline & & & & \\
\hline & $\bar{n}$ & $\%$ & $\bar{n}$ & $\%$ \\
\hline \multicolumn{5}{|l|}{ Physical violence during the last 12 months, and/or at any time in your life before that } \\
\hline Threatened to hurt you or others you are found of? & 65 & 81.3 & 36 & 29.0 \\
\hline Threatened to kill you? & 53 & 67.1 & 22 & 17.6 \\
\hline Obstructed you from moving around freely, or grabbed and hold you with force? & 65 & 82.3 & 61 & 48.8 \\
\hline Hit you with an open hand? & 53 & 67.1 & 46 & 36.8 \\
\hline Threw a hard object at you? & 45 & 57.0 & 33 & 26.4 \\
\hline Hit you with a clenched fist, a hard object or kicked you? & 55 & 68.8 & 28 & 22.6 \\
\hline Had a stranglehold or tried to strangle you? & 44 & 55.7 & 21 & 16.8 \\
\hline Assaulted you with a knife or other type of weapon? & 28 & 35.4 & 8 & 6.4 \\
\hline Hit your head against an object or against the wall or the floor? & 40 & 50.0 & 13 & 10.4 \\
\hline Forced you to have sex against your will? & 49 & 63.6 & 28 & 22.4 \\
\hline Behaved violent toward you in other way? & 73 & 93.6 & 71 & 53.6 \\
\hline Repeatedly followed you, phoned or visited you at work so that you became afraid? & 55 & 69.6 & 21 & 16.8 \\
\hline \multicolumn{5}{|l|}{ Psychological violence frequently or very frequently } \\
\hline Called me names & 62 & 77.5 & 20 & 15.9 \\
\hline Swore at me & 57 & 72.2 & 17 & 13.6 \\
\hline Yelled and screamed at me & 61 & 76.3 & 16 & 12.7 \\
\hline Threated me inferior & 63 & 78.8 & 20 & 15.9 \\
\hline Monitored my time and demanded to know where I was & 53 & 66.3 & 15 & 12.0 \\
\hline Used money or made important financial decisions without talking to me & 49 & 61.3 & 16 & 12.7 \\
\hline Was jealous or suspicious of my friends & 55 & 70.5 & 22 & 17.5 \\
\hline Accused me for having an affair with another & 35 & 43.2 & 12 & 9.6 \\
\hline Interfered my relationship with other family members & 35 & 67.9 & 12 & 9.5 \\
\hline Tried to keep me from doing things to help myself & 43 & 55.8 & 8 & 6.4 \\
\hline Restricted my use of the telephone & 33 & 41.3 & 8 & 6.5 \\
\hline Told me my feelings were irrational or crazy & 61 & 76.3 & 19 & 15.2 \\
\hline Blamed me for his problems & 61 & 76.3 & 24 & 19.4 \\
\hline Tried to make me feel crazy & 59 & 73.8 & 13 & 10.5 \\
\hline
\end{tabular}


abused women in the random sample, further forced to have sex (64\% versus $22 \%$, respectively) and stranglehold (56\% versus $17 \%$ ) (Table 2 ). Acts of psychological violence as verbal/emotional abuse about calling her names, sworing, yelling and acts related to jealousy frequently/ very frequently were reported by more than $70 \%$ in the "women seeking help" group. These acts were also the most frequently acts reported among the abused women in the random sample, however much lower (10-17.5\%). Acts related to dominance and control as jealousy, monitoring her time, making important financial decision without talking to her showed the same patterns however it was less frequently reported.

The SF-12 scores were significantly different among the groups (Fig. 1). All domains in SF-12 were significantly lower $(p<0.001)$ among the women seeking help after domestic partner abuse compared to abused women in the random sample. Further the abused women in the random sample had significant lower health related quality of life (SF12) compared to the not abused women in the random sample. The social functioning and the scores in the mental health domain were two standard divisions below the normal population (Fig. 1).

When comparing the random sample with the population norms in HRQoL in Norway, we found significantly higher scores $(p<0.01)$ in all domains except mental health, social functioning and bodily pain (Fig. 2).

\section{Discussion}

Women who had experienced partner abuse reported lower HRQoL in all domains compared to women who had not experienced IPV. The social functioning and mental health scores were two standard divisions below the norm in population scores among women of the same age in Norway, as found in our earlier study [6]. These scores are very low, and indicate a risk of suicide [11]. The women seeking help after domestic partner abuse, also had especially low scores in mental health. New studies from Iran, China and USA confirm the significantly lower quality-of-life scores among abused compared to non-abused women [14, 19, 20].

Serious threats, such as threats to kill you or someone you care for, reported by more than two thirds of the sample of women seeking help and nearly one third in among abused women in the random sample, shows that these acts are valid related to IPV The relationship between IPV and quality of life, highlights the fact that violence destroy the quality of life in these women's lives.

The very low mental health score found in our study in 2006 [6] is also found in the present study, and it is still lower than scores reported in other studies [19-22]. This may be an effect of feeling even more left out and alone when experiencing partner violence in a society where the level of gender equality is high. However, "gender equality" refers to social norms that may differ

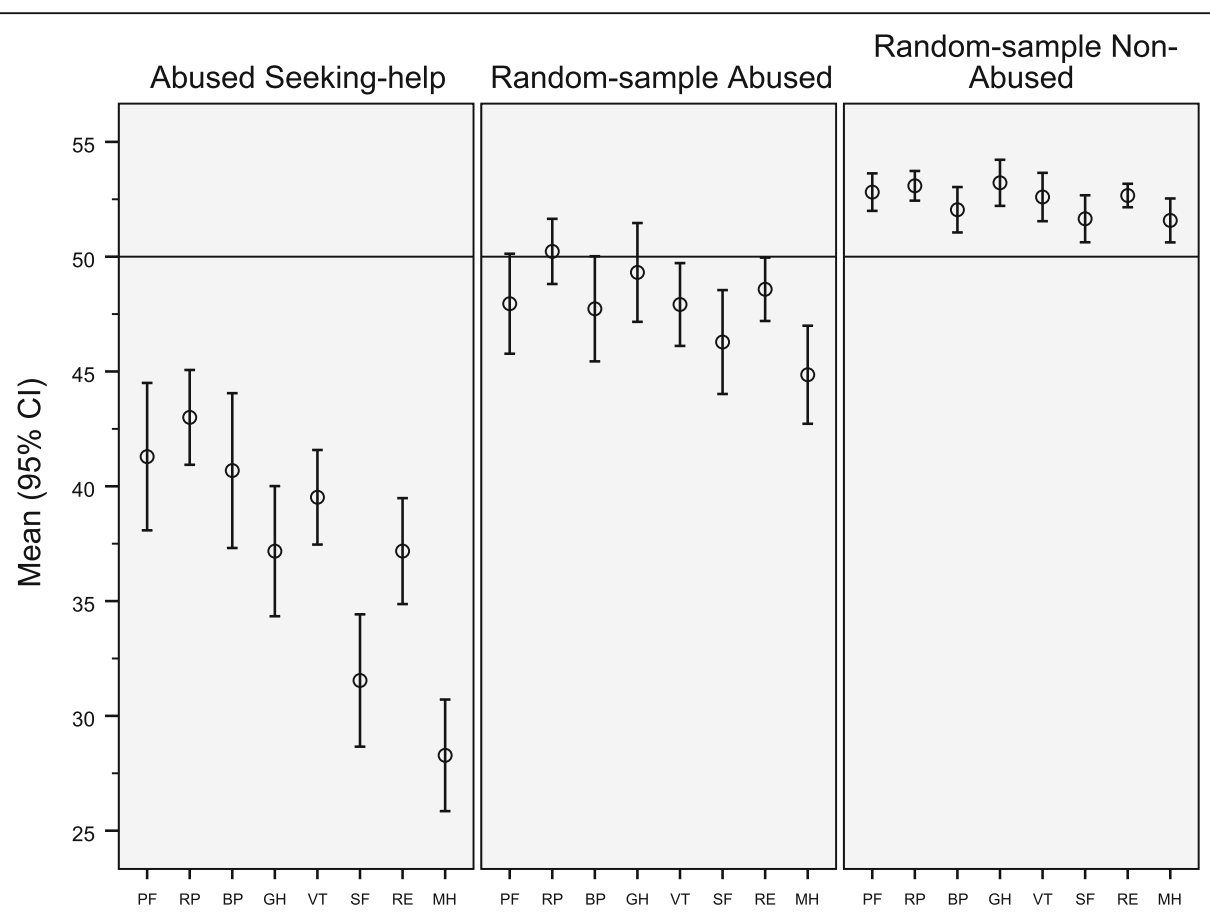

Fig. 1 Mean age-standardized score and 95\% confidence interval (Cl) for the eight SF-12 dimensions among "abused women seeking help", "random sample of abused women" and "random sample of not abused women". The mean score of the general Norwegian female population is 50 for all scales. (PF = Physical Function, RP = Role Physical, $\mathrm{BP}=$ Bodily Pain, GH= General Health, VT=Vitality, SF = Social Function, RE = Role Emotional, $\mathrm{MH}=$ Mental Health) 


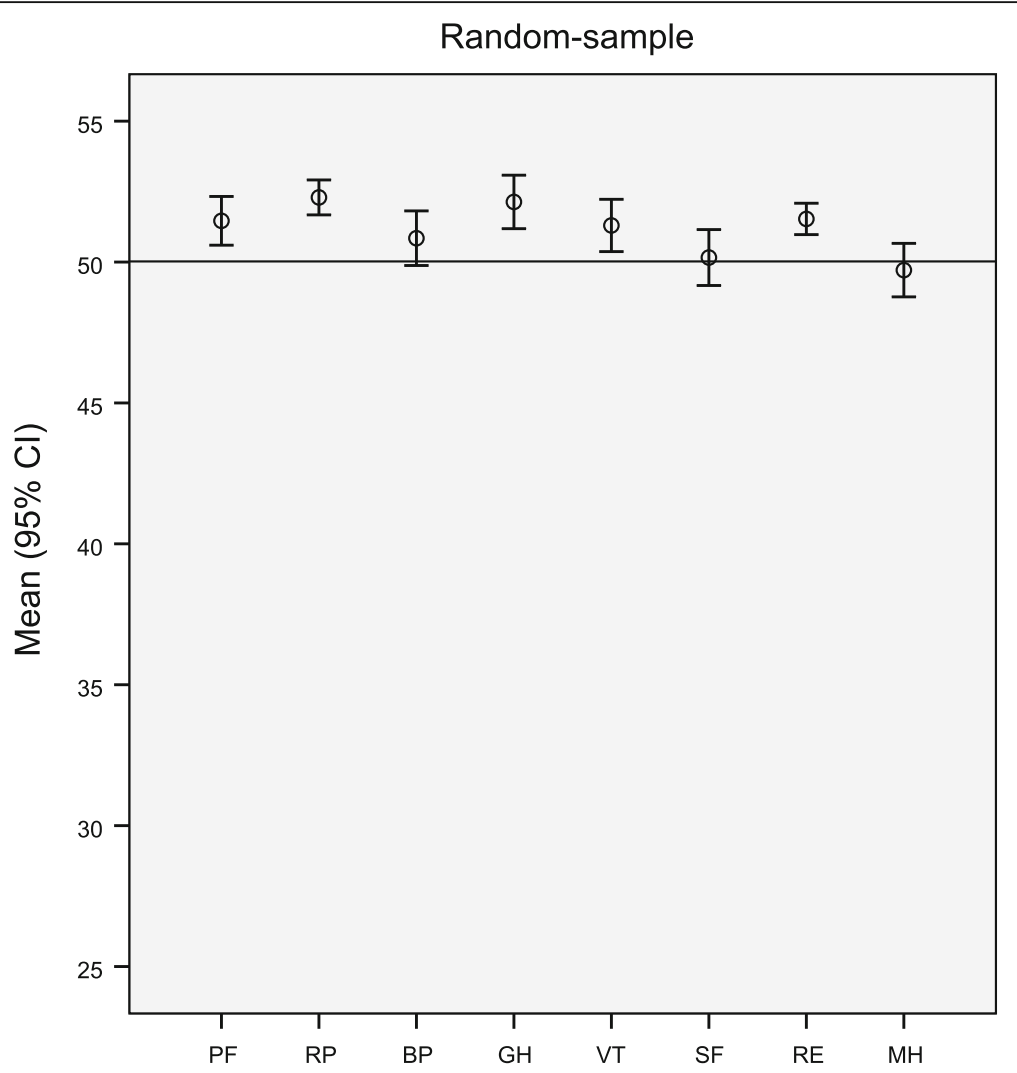

Fig. 2 Mean age-standardized score and 95\% confidence interval (CI) for the eight SF-12 dimensions in the total random sample of women. The mean score of the general Norwegian female population is 50 for all scales. (PF = Physical Function, RP $=$ Role Physical, BP $=$ Bodily Pain,

$\mathrm{GH}=$ General Health, $\mathrm{VT}=$ Vitality, $\mathrm{SF}=$ Social Function, $\mathrm{RE}=$ Role Emotional, $\mathrm{MH}=$ Mental Health)

from personal norms in close relationships among partners. Many men may still experience a need to feel more powerful than women. These factors may be related to the Nordic Paradox [6].

The events that trigger and most of the acts of men's violence against women are found to be remarkably consistent throughout the world [4]. Power and control strategies that keep women in the subordinate position is central. Some norms as "blaming the victim" and "keep your private problems private" make it difficult to tell about IPV problems. These norms have been slowly changing during the last decades and may change more rapidly in the wake of the Meetoo campaign. Shame and guilt are negative feelings and these emotions are strongly related to low quality of life. The deepest feeling of shame is defined as a strong feeling of not being worthy as a human being [23].

In our earlier one-year follow-up study among abused women in Norwegian women's shelters, the quality of life was significantly improved with regard to vitality, social function and mental health among those who had left their partner, but their low physical health scores were not improved [24]. This may indicate that recovery from bodily effects of IPV requires more time and maybe intervention.
The higher scores in the general population sample in this study with regard to "physical health" "physical health role" and "role- emotional" may be related to the character of this study, as it was called "Work, health and safety survey" and includes a sample with higher employment rates and therefore also higher HRQoL scores. In addition, others have found that women experiencing IPV seldom answer questionnaires about IPV because they are afraid of reprisals from their husband. The more IPV experienced, the more infrequently they respond to such questionnaires [25].

The response rate was low, but this is common in these kinds of studies $[25,26]$ and may be a result of the very private and taboo nature of the questions asked. Strength of the study is the inclusion of both women seeking help and a normal population. As this study is a cross sectional study we can only conclude on associations. The reason why abused women have low quality of life cannot be stated by this study. The nature of the question may also influence the way of responding. In the population study, the participants answered the questions at home, and might be under influence of others. This may have led to different reporting from this group, compared to the answers from the abused women. However, we cannot 
state this with certainty. The high frequency of different acts of IPV reported by "women seeking help" confirm that women seeking help because of IPV must be prioritized, and danger assessment as well as safety planning must be done. Using SF-12 in measuring HRQoL among abused women provides an opportunity for comparing the results with the general female population and with other relevant studies abroad.

\section{Conclusion}

Intimate partner violence is clearly associated with low quality of life. We found a pattern similar to the pattern found in the previous Norwegian study among women seeking help after domestic partner abuse. This highlight the need for actions to reduce the intimate violence against women and greater awareness among health professionals to address this issue.

\section{Abbreviations \\ HRQoL: Health-related quality of life; IPV: Intimate partner violence}

\section{Acknowledgements}

We thank the survey respondents. We also want to thank the Norwegian ExtraFoundation for Health and Rehabilitation through EXTRA funds for financially support.

\section{Funding}

The Norwegian ExtraFoundation for Health and Rehabilitation supported this project financially through EXTRA funds. The Norwegian ExtraFoundation for Health and Rehabilitation is an institution consisting of 28 voluntary health and rehabilitation organizations. The Norwegian ExtraFoundation is licensed to operate the national TV game EXTRA. Proceeds from the game go towards strengthening the work of voluntary humanitarian organizations in preventive health care, rehabilitation and research in Norway. All voluntary humanitarian/socially dedicated organizations and professional organizations for the functionally disabled in Norway may apply for funds regardless of membership in the foundation.

\section{Availability of data and materials}

This data are very sensitive data and there is a restriction about the use from Regional Committee for Medical and Health Research Ethics- Region West in Norway (2009/2591). Only the present four authors have access to the data today, and a special request to must be made to the Committee to be allowed to include others.

\section{Authors' contributions}

KA made substantial contributions developing the study design, the questionnaire, get founding and obtaining data analysis and drafted the manuscript. BEM has made substantial contributions to conception and design. BEM, VB and TM made substantial contributions in analysis and interpretation of data. All have been involved in drafting the manuscript and revising it critically for important intellectual content. They have also given final approval of the version to be published.

\section{Ethics approval and consent to participate}

All procedures performed in this study were reviewed and approved by Regional Committee for Medical and Health Research Ethics- Region West in Norway (2009/2591) and were done in accordance with the 1964 Helsinki declaration.

\section{Consent for publication}

Not Applicable.

\section{Competing interest}

The authors declare that they have no competing interest.

\section{Publisher's Note}

Springer Nature remains neutral with regard to jurisdictional claims in published maps and institutional affiliations.

\section{Author details}

${ }^{1}$ Faculty of Health and Social Sciences/ Department of Welfare and Participation, Western Norway University of Applied Sciences, Haugeveien 28, 5005 Bergen, Norway. ${ }^{2}$ National Centre for Emergency Primary Health Care, Uni Research Health, Bergen, Norway. ${ }^{3}$ Centre for International Health, Department of Global Public Health and Primary Care, University of Bergen, Bergen, Norway. ${ }^{4}$ Uni Research Health, Bergen, Norway.

Received: 7 April 2017 Accepted: 23 August 2018

Published online: 04 September 2018

\section{References}

1. Bonomi AE, Thompson RS, Anderson M, Reid RJ, Carrell D, Dimer JA, Rivara FP. Intimate partner violence and women's physical, mental, and social functioning. Am J Prev Med. 2006;30(6):458-66.

2. Campbell JC. Health consequences of intimate partner violence. Lancet. 2002;359(9314):1331-6.

3. Howard LM, Oram S, Galley H, Trevillion K, Feder G. Domestic violence and perinatal mental disorders: a systematic review and meta-analysis. PLoS Med. 2013;10(5):e1001452.

4. Krug EG, Dahlberg LL, Mercey JA, Swi AB,Lorazo R, World report on vioence and health.Geneve: World Health Organization.

5. Neroien Al, Schei B. Partner violence and health: results from the first national study on violence against women in Norway. Scand J Public Health. 2008;36(2):161-8.

6. Gracia E, Merlo J. Intimate partner violence against women and the Nordic paradox. Soc Sci Med. 2016:157:27-30.

7. Alsaker K, Moen BE, Nortvedt MW, Baste V. Low health-related quality of life among abused women. Oual Life Res. 2006;15(6):959-65.

8. Beredskapsdepartementet J-o: "Et liv uten vold" . Handlingsplan mot vold i nære relasjoner 2014-2017. In.; 2014.

9. Dichter ME, Marcus SC, Wagner C, Bonomi AE. Associations between psychological, physical, and sexual intimate partner violence and health outcomes among women veteran VA patients. Soc Work Ment Health. 2014;12(5-6):411-28.

10. Laffaye C, Kennedy C, Murray BS. Post-traumatic stress disorder and healthrelated quality of life in female victims of intimate partner violence. Violence Vict. 2003;18(2):227-38.

11. Wyrwich KW, Bullinger M, Aaronsen N. Estimating clinically significant differences in quality of life outcomes. Oual Life Res. 2005;14:285-95.

12. Devries K, Watts C, Yoshihama M, Kiss L, Schraiber LB, Deyessa N, Heise L, Durand J, Mbwambo J, Jansen $\mathrm{H}$. Violence against women is strongly associated with suicide attempts: evidence from the WHO multi-country study on women's health and domestic violence against women. Soc Sci Med. 2011;73(1):79-86

13. McLaughlin J, O'Carroll R, O'Connor R. Intimate partner abuse and suicidality: a systematic review. Clin Psychol Rev. 2012;32(8):677-89.

14. Dillon G, Hussain R, Loxton D, Rahman S. Mental and physical health and intimate partner violence against women: a review of the literature. Int J Fam Med. 2013;2013(2013):313909. https://doi.org/10.1155/2013/313909.

15. Tolman RM. The validation of the Psychological Maltreatment of Women Inventory. Violence Vict. 1999;14(1):25-37.

16. Ware JE Jr, Kosinski M, Keller SD. A 12-item short-form health survey: construction of scales and preliminary tests of reliability and validity. Med Care. 1996;34(3):220-33.

17. Jakobsson U. Using the 12-item short form health survey (SF-12) to measure quality of life among older people. Aging Clin Exp Res. 2007;19(6):457-64.

18. Müller-Nordhorn J, Roll S, Willich S. Comparison of the short form (SF)-12 health status instrument with the SF-36 in patients with coronary heart disease. Heart. 2004;90(5):523-7.

19. Tavoli Z, Tavoli A, Amirpour R, Hosseini R, Montazeri A. Quality of life in women who were exposed to domestic violence during pregnancy. BMC Pregnancy Childbirth. 2016;16:19. https://doi.org/10.1186/s12884-016-0810-6.

20. Gharacheh M, Azadi S, Mohammadi N, Montazeri S, Khalajinia Z. Domestic violence during pregnancy and women's health-related quality of life. Glob J Health Sci. 2015;82:27. 
21. Leung TW, Leung WC, Ng EH, Ho PC. Quality of life of victims of intimate partner violence. Int J Gynaecol Obstet. 2005;90(3):258-62.

22. Taft A, O'Doherty L, Hegarty K, Ramsay J, Davidson L, Feder G. Screening women for intimate partner violence in healthcare settings. Cochrane Database Syst Rev. 2013;4 CD007007.

23. Alsaker $\mathrm{K}$, Moen BE, Baste V, Morken T. How has living with intimate partner violence affected the work situation? A qualitative study among abused women in Norway. J Fam Violence. 2016;31(4):479-87. https://doi.org/10. 1007/s10896-016-9806-2.

24. Alsaker K, Moen BE, Kristoffersen K. Health-related quality of life among abused women one year after leaving a violent partner. Soc Indic Res. 2008;86:497-509.

25. Waltermaurer E. Issues in estimating the prevalence of intimate partner violence. J Interpers Violence. 2003;18:959-74.

26. Gracia E. Unreported cases of domestic violence against women: towards an epidemiology of social silence, tolerance, and inhibition. J Epidemiol Community Health. 2004;58(7):536-7.

Ready to submit your research? Choose BMC and benefit from:

- fast, convenient online submission

- thorough peer review by experienced researchers in your field

- rapid publication on acceptance

- support for research data, including large and complex data types

- gold Open Access which fosters wider collaboration and increased citations

- maximum visibility for your research: over $100 \mathrm{M}$ website views per year

At $\mathrm{BMC}$, research is always in progress.

Learn more biomedcentral.com/submissions 